\title{
Giving voice to India's entrepreneurs
}

\author{
Gayatri Saberwal \\ A survey of stakeholders in the Indian biotech sector reveals three major challenges that will need to be addressed to \\ spark further entrepreneurial activity.
}

\begin{abstract}
ndia needs a burgeoning biotech ecosystem that can both create and develop new low-cost products and bring them to market. Previous studies have revealed several hurdles to achieving this goal, including a lack of ready sources of risk capital for financing, an insufficient critical mass of innovative companies, and numerous intellectual property (IP), regulatory and reimbursement hurdles (Nat. Biotechnol. 24, 499-501, 2006 and Nat. Biotechnol. 25, 403-417, 2007). During 2010 and 2011, I spoke with representatives from more than 60 Indian biopharmaceutical companies to gain a more detailed understanding of the factors that are holding back the growth and maturation of Indian biotech (see Box 1 for methodology). In the following article, I present three key themes that emerged from these interviews and summarize the implications for further growth of the sector.
\end{abstract}

\section{A shortage of qualified personnel}

One major impediment to the development of entrepreneurial activity in the Indian biotech sector is the shortage of personnel-a problem that has its roots in graduate education. Most educational institutions in India, whether at the bachelor's or master's level, are ill equipped for lab work for either biotech or bioinformatics. This lack of facilities exists even though institutional leadership knows that this type of work is needed for proper training and that academic syllabi often require not only lab-based courses but also a semester-long, lab-based project.

Gayatri Saberwal is a faculty member at the NEN Wadhwani Centre for Excellence in Entrepreneurship Education, Institute of Bioinformatics and Applied Biotechnology, Biotech Park, Electronics City Phase I, Bangalore, India.

e-mail: gayatri@ibab.ac.in
This is a failing of the university management process; indeed, students are sometimes required to find this type of training on their own, at their own cost, to complete their degrees.

Startup companies have often stepped in to fill this educational gap, providing from a few days to up to six months of training for students or recent graduates. Training charges are in the range of $\$ 90-\$ 150$ per participant per month, so for some startup companies this type of service can bring in a small profit (and has served as an alternative source of revenue to supple- ment the small amounts of risk capital, angel or family funding available). Indeed, until recently, the arrangement served both students and companies, providing students with the necessary experience while bringing companies much needed revenue (from student training fees) and manpower.

In recent times, however, the number of students entering such programs has dwindled. This is partly because the growth of the biotech and bioinformatics sector has failed to live up to expectations in terms of job creation for graduates, who have in turn looked to other sectors with better prospects.

\section{Box 1 Survey methodology}

Between July 2010 and September 2011, 61 interviews were conducted with senior people in or associated with young biopharmaceutical firms in India. Of these, 5 were discarded as uninformative, leaving 56 that were considered useful. The categories of people interviewed were current or former CEOs, CSOs and other senior executives of young companies, consultants, investors and occasionally academics or individuals from large local firms, multinationals or foreign companies. The entities of interest were those doing preclinical research and associated work, and very occasionally, work related to clinical research, medicinal plants, diagnostics or medical devices. The author is based in Bangalore, and therefore most interviews were conducted there, usually in person though in some cases over the telephone (33 cases in all). The interviewees were based in Bangalore or were people visiting from elsewhere (in India or abroad). In addition, the author spoke with individuals in other cities in India over the telephone (5 cases) and visited Hyderabad and Delhi to conduct some interviews in person (10 cases). Some interviewees are located abroad, in Singapore, Sweden or the US, and they too were interviewed over the telephone or using Skype (8 cases). Most interviewees were interviewed only once. All the interviews were conducted by the author alone, except seven early ones that were conducted along with a postdoctoral fellow. All but four were conducted with a single interviewee, and in the exceptions there were two respondents. The author usually spoke with only one person from a given organization. The interview format was semi-structured and evolved with each interview. A given interview ranged from 15 minutes to 2 hours, the average being 57 minutes. Although the conversations were not recorded, detailed notes were made either during the course of the interview (in case it was being conducted over the phone or using Skype) or from memory immediately afterward (in case it was face-to-face). Clarification and/or follow-up interviews were conducted in July and August 2012. Seven of these were over the phone and three by e-mail. Six were earlier interviewees and four were new individuals. 
The sector's human resourcing ills go beyond a lack of relatively inexperienced graduates entering the workforce; many well-trained, experienced people seeking a rich R\&D environment are frustrated at the lack of suitable opportunities and appropriate pay scales in Indian biotech. The difficulty in finding appropriately qualified talent is clearly contributing to the slow growth of Indian life science ventures.

Certain areas of expertise are particularly thin on the ground. With the emergence of biosimilars in European markets (Nat. Biotechnol. 28, 917-924, 2010) and moves in the US to provide a regulatory pathway, interest is growing in India in the biosimilar space. Most of the biologics currently manufactured by Indian firms are copycat molecules that have not been authorized as biosimilars-these biologic molecules are usually produced from imported clones, and the scale-up processes adopted to manufacture them exploit imported standard operating procedures. This is perfectly legal, of course, but process development has not received adequate emphasis in India, and respondents noted that the country lacks sufficient trained employees in this area. To move ahead, India needs these capabilities in greater abundance. It is not as if the country has not tried; there have been attempts to transfer process development technologies from academia, but results have been mixed.

All these problems with recruitment of key personnel have repercussions for the entrepreneurs themselves. Entrepreneurs often either cannot afford or cannot find experienced senior management, and thus the day-to-day business becomes all consuming, preventing them from spending sufficient time to consider growth, diversification or serial entrepreneurship. Young Indian CEOs who lack experience-perhaps because there is an inadequate pool of experienced serial entrepreneurs to offer advice and network opportunities-often have trouble delegating and then find themselves doing minutiae, such as handling the petty cash, and this situation can continue even years after a company has been founded.

\section{Limited resources, facilities and support services}

Another key challenge faced by Indian entrepreneurs is the difficulty of accessing appropriate state-of-the-art equipment and other laboratory facilities. National research institutions and universities sometimes allow individual entrepreneurs to make use of their facilities; the problem is that this seems to happen on an ad hoc basis in a somewhat idiosyncratic process based on personal rapport between the scientist and entrepreneur in question.

The situation may improve, however, as an independent organization, India's Biotechnology Industry Research Assistance Council (BIRAC), based in Delhi, has a program to strengthen existing bioincubators and establish new ones. It is planned that these incubators, even if part of an academic institute, will host startups founded by individuals from all over the country.

After a national call for applications, several institutions have been selected for funding on the basis of a combination of past track record, potential for success and their geographic distribution around the country. Examples include ICICI KP in Hyderabad, NCL Innovations in Pune and some of the Indian Institutes of Technology. These incubators will have sophisticated laboratory facilities that nonresident young companies will also be able to access on a pay-per-use basis. Critical to the success of these incubators, and in particular their instrument facilities, will be their commitment to providing high-quality and timely service to their clients. In Indian academia there has been a tendency for research goals to trump service goals, an issue that needs to be addressed squarely if techno-entrepreneurship is to flourish.

According to interviewees, access to the literature is another resource issue, especially for Indian biotech companies with innovative programs in areas of cutting-edge science. Barring public institutions in certain networks, neither academic institutions nor companies can access the bulk of the international scientific literature, mainly because of the prohibitive costs of site licenses or subscriptions. Although some of the libraries at major Indian academic institutions are open to corporate membership, the mechanism to obtain articles can be archaic and often seems designed to deter access. If the need for research papers is only occasional, informal methods such as e-mailing friends or approaching people in your network can be adequate. But companies that rely heavily on literature often request papers from clients or require clients to pay for article access. This increases the cost of the work, which clients are unhappy with, and has affected the kinds of projects that can be undertaken. Many firms (and other institutions) would benefit from an efficient system of lower-cost, payper-use access to journal articles in digital form. Only the government can enable this.

In terms of resources that could facilitate the creation of more business oppor- tunities in the Indian biotech sector, the present survey also revealed two distinct areas that could benefit from government investment: the creation of comprehensive and diverse compound libraries and greater availability of contract manufacturing facilities.

Several interviewees mentioned the need for better access to large compound libraries from either the public and private sectors. Many Indian firms create sets of compounds on demand, so it is not as if the country does not have the scientific capability. However, creating and maintaining a library is an expensive process, and without the immediate revenue from a client, it is not a feasible approach for most Indian biotech companies.

One possible solution would be for the Indian government to create a collection of compounds, accessible by Indian companies, in a manner similar to the Molecular Libraries Initiative of the US National Institutes of Health. This would be a tremendous boon to product-minded startups.

Another service highlighted by survey respondents as beneficial for Indian businesses would be the provision of more contract manufacturing facilities. Several interviewees mentioned that once their company has a construct and has identified the right expression system, there are often few options in terms of Indian entities to which they can turn for manufacturing scale-up. Many firms offering the required contract manufacturing capabilities also make their own products and/or biosimilars, which creates confidential business information and IP concerns.

In this respect, there is good news on the horizon as some plans for contract manufacturing plants are afoot. Indeed, Kemwell, of Bangalore, has formed a partnership with Boehringer Ingelheim, of Ingelheim, Germany, to create a large contract manufacturing facility in Bangalore, which is scalingup pilot production.

\section{Government liaison and support}

Young biotech firms need to engage with the government on various issues. On the basis of feedback from interviewees, it appears that whereas some departments are supportive of young companies, the attitude of others ranges from indifference to active opposition. This leaves young biotech companies with a range of issues to overcome.

Entrepreneurs can participate in various government programs established to assist them, but those seeking help from officials may need to travel to Delhi several times regarding funding proposals or regulatory 
clearance. This adds up in terms of time and expense, and numerous respondents questioned whether this was necessary.

Interviews with biopharmaceutical stakeholders also revealed that there is a lack of clarity in government rules for what must be done to obtain specific clearances, such as being recognized as an R\&D company or being permitted to import animals. The production of authoritative 'to-do' documents, including a commitment to timelines for clearance at each step, would save companies immense time and money. Having clearer regulatory procedures would also help alleviate concerns among investors and should help attract more private capital to the industry.

The difficulties encountered by entrepreneurs in negotiating byzantine government regulations is illustrated by current rules on funding and IP. Under the present system, the Indian government has the following provision: if a firm receives government funding, the company must use its IP for "commercial exploitation" by one year after the "date of patent" or two years from the completion of the project. According to respondents, not only is it unclear whether the "date of patent" means the date of patent issue but also, more importantly, companies that fail to commercialize their product within the stipulated time frame may have their IP confiscated by the government-a major disincentive for entrepreneurs and investors.

This clause has been widely criticized and is clearly a major impediment to investment in biopharmaceutical companies, for which timelines are often decades long and substantial funding and resources are required to propel a commercialization program forward. Entrepreneurs are of course keen to establish healthy revenue streams, but the short timeline presented by the government is unrealistic. Furthermore, should the government funds be substantially smaller than previous investments, it is unrealistic to expect a firm's earlier investors to agree to this provision and risk losing integral IP. Clearly, this clause is harming the industry and needs to be examined.

Similarly, respondents from innovative diagnostics and medical devices firms have faced specific challenges responding to government tenders. For example, unless a company has already supplied a large order at least once, it may not even be eligible to bid for a government contract. What is more, interviewees indicated that such tenders are sometimes drafted to favor certain companies that have supplied the government in the past. Finally, a company that has previously supplied equipment to the government may blackmail officials regarding the continuing supply of reagents or maintenance for use of that company's instruments, unless a renewal or award of a new tender is forthcoming.

These anticompetition issues hurt young firms. In the US, in contrast, there is a requirement that almost a quarter of government orders go to young companies (http:// www.sba.gov/content/strategies-growthfederal-contracting). A similar requirement for Indian firms would go a long way to addressing these problems.

\section{Conclusions}

In 2006, I identified nine categories of founders of biopharmaceutical companies in India (Nat. Biotechnol. 24, 499-501, 2006). On the basis of feedback from the present survey, a 10th category can now be addedgraduating students (bachelor's level or higher) who become neophyte entrepreneurs. This group is being helped somewhat by India's Department of Biotechnology program, the Biotechnology Entrepreneur Student Team, which provides cash and connections.

However, the fact is that young entrepreneurs-and all the other types of founders that create life science ventures in India-would benefit from progress in several areas. The Indian biotech sector has always been hampered by a lack of risk capital, a lack of companies with innovative discovery programs, and a suboptimal IP, regulatory and reimbursement environment (Nat. Biotechnol. 24, 499-501, 2006 and Nat. Biotechnol. 25, 403-417, 2007).

In addition to the above general challenges faced by the Indian biotech sector, the qualitative survey feedback reported here highlights three specific areas-a shortage of qualified personnel, underdeveloped resources, infrastructure and services, and suboptimal government liaison and rulesthat require attention to foster an environment more conducive to the growth of an innovative biotech sector.

In the case of attracting talent, for example, it is possible that the government could pay salaries of particularly experienced scientists for a fixed time period in young companies. Indeed, BIRAC has established several new programs, including the Biotechnology Ignition Grant program, which provides up to $\$ 90,000$ for 18 months to qualified personnel. This would certainly go some way toward helping young companies attract the talent they need to grow.

One other observation is that the Indian educational system has always kept scientists and businesspeople apart. A lack of familiar- ity with the scientific enterprise means businesspeople in India are often uncomfortable taking an $\mathrm{R} \& \mathrm{D}$ risk and therefore often shy away from partnering with a technopreneur. Furthermore, business people do not fully understand the nuances of science and may be unable to sell an innovative life science venture's story to an investor or even talk knowledgeably with business clients that could provide monies from research collaborations or licensing. Finally, the business professionals searching for companies to run have many sectors to choose from (for example, information technology, finance and/or infrastructure, and many of these enterprises have a shorter gestation period than biotech startups, thus proving more attractive.

Overall, the Indian biotech sector has too few success stories and lacks a sufficient critical mass of serial entrepreneurs. In the case of biotech, there seem to be multiple reasons. First is that there have not been enough good exits to establish an individual's or a team's pedigree, and without that record, funders are not likely to commit to a new project. Second, the life science sector (including such specialties as innovative drug discovery, contract research, diagnostics or medical devices) is rapidly changing and lacks established business models that have been tried and tested in India. Finally, in India a founder selling their company has to sign a noncompete clause and thus is discouraged from starting a business in the same sector.

Given the small number of biotech successes in India, perhaps it is not so surprising that local entrepreneurs are not more outward looking. But it is striking that the Indian sector lacks one type of business relationship that should exist-an equal partnership between a local Indian person and someone based abroad, with each having access to different assets. These relationships are found in other countries but not in India. There may be any number of reasons for this: perhaps the biotech ecosystem in India is too young, perhaps there are not enough Indian entrepreneurs with international reputations and recognition or perhaps there is a lack of established business models for this type of partnership or even a lack of trust between locals and those working abroad.

Thus, India's biotech sector is underdeveloped. Lack of existing biotechs as well as conservatism among current pharmaceutical manufacturers and makers of generics leads to too few spinoffs. Across the biotech world, spinoffs are often spawned from older, public companies, but in India there seems to be a decreasing interest in this, regardless of tax and other benefits. Partly, this is because large generics firms that might consider setting up a services or R\&D company are wary of under- 
performing units that could impact the parent firm's stock.

Looking forward, it is clear that the Indian biotech sector has made progress, and entrepreneurs today do not face struggles as great as those of their predecessors from even a couple of decades ago. However, considerable room for improvement still exists. On the basis of the survey reported here, there seem to be too many outstanding challenges and too few catalysts to enable rapid growth in the number of companies and their rate of maturation in Indian biotech anytime soon.

\section{ACKNOWLEDGMENTS}

I would like to sincerely thank all the interviewees who were so generous with their time and their insights. The work presented here has been entirely funded by the Institut Mérieux as part of a larger grant supporting my work, for which I am very grateful.

\section{COMPETING FINANCIAL INTERESTS}

The author declares competing financial interests: details are available at http://www.nature.com/ doifinder/10.1038/nbt.2493.

Corrected after print 30 April 2013.

For more content on bioentrepreneurism, visit our Trade Secrets blog.

http://blogs.nature.com/trade_secrets/ 


\section{Corrigendum: Giving voice to India's entrepreneurs}

Gayatri Saberwal

Nat. Biotechnol. 31, 104-107 (2013); published online 22 January, 2013; corrected after print 30 April 2013

In the version of this article initially published online, it was suggested that a $\$ 90,000$ grant would be used to cover salaries for 18 months. The grant is not restricted to salaries. The error has been corrected for the PDF and HTML versions of this article. 